\title{
Home Care for People with Suspected or Confirmed Coronavirus Disease “Covid-19"
}

\section{Mohsen MM*}

Faculty of Nursing, Menoufia University, Egypt

*Corresponding author: Magda M Mohsen, Faculty of Nursing, Menoufia University, Menoufia Governorate-Egypt-Sheben El-Kom Gamal Abd el-Naser st-Faculty of Nursing, Egypt, Tel: 01006625575; Email: magda.mohsen2000@hotmail.com

\section{Commentary}

Volume 4 Special Issue 1

Received Date: June 29, 2020

Published Date: July 14, 2020

DOI: $10.23880 /$ nhij-16000S1-003

\section{Abstract}

Background: The rapid spread of coronavirus disease that emerged in late 2019, has been labeled a Public Health Emergency of International Concern by the World Health Organization. Coronavirus disease "Covid-19" is a major pandemic affecting most parts of whole world. The aim of this commentary was to describe the current situation around the world.

Methodology: survey the online data about COVID 19, since it is a new virus disease that needs much effort to determine who is it, how to deal with infected persons or suspected persons, also how to deal with contacts, how to communicate with others in the community.

Results: World Health Organization and different organizations did huge efforts and determines specific precautions in order to minimize its spread.

Conclusion: Controlling the outbreak required the combined efforts of ordinary citizens, political and religious leaders, community workers, and none Governmental Organizations and general public to follow the recommended precautions plan especially in home care.

\section{Introduction}

The rapid spread of coronavirus disease that emerged in late 2019, has been labeled a Public Health Emergency of International Concern by the World Health Organization [1]. Coronavirus disease "Covid-19" is a major pandemic affecting most parts of whole world [2]. The international response to the Coronavirus disease "Covid-19" was truly assertive, and needs an urgent public health intervention. Controlling the outbreak required the combined efforts of ordinary citizens, political and religious leaders, community workers, and none Governmental Organizations.

According to the current evidence, COVID-19 virus is primarily transmitted between people via respiratory droplets and contact routes. Droplet transmission occurs when a person is in close contact (within 1 meter) with an infected person and exposure to potentially infective respiratory droplets occurs, for example, through coughing, sneezing or very close personal contact resulting in the inoculation of entry portals such as the mouth, nose or conjunctivae (eyes) [3-5]. Transmission may also occur through fomites in the immediate environment around the infected person [6]. Therefore, transmission of the COVID-19 virus can occur directly by contact with infected people, or indirectly by contact with surfaces in the immediate environment or with objects used on or by the infected person.

There is also the possibility of transmission from people who are infected but have not yet developed symptoms; this is called pre-symptomatic transmission. The incubation period for COVID-19, which is the time between exposure to the virus and symptom onset, is on average 5-6 days, but 
can be as long as 14 days [7,8]. Additionally, data suggest that some people can test positive for COVID-19, via polymerase chain reaction (PCR) testing 1-3 days before they develop symptoms [9]. People who develop symptoms appear to have higher viral loads on or just prior to the day of symptom onset, relative to later on in their infection [10].

As until know still do not have a very effective drug of choice to cure the corona virus. So it is a good time to challenge and apply some of effective community prevention activities which can be introduced into the community in a larger scale. As some of the activities which can be recommended to the community or to asymptomatic COVID 19 patients apart from social distancing, hand wash and wearing masks which has already been followed or advised to the community by world health organization.

WHO's guidance on the type of respiratory protection to be the use of masks as part of a comprehensive package of the prevention and control measures that can limit the spread of certain respiratory viral diseases, including COVID-19. Masks can be used either for protection of healthy persons (worn to protect oneself when in contact with an infected individual) or for source control "worn by an infected individual to prevent onward transmission" [11].

However, the use of a mask alone is insufficient to provide an adequate level of protection or source control, and other personal and community level measures should also be adopted to suppress transmission of respiratory viruses. Whether or not masks are used, compliance with hand hygiene, physical distancing and other infection prevention and control measures are critical to prevent human-tohuman transmission of COVID-19 (Figures 1-3).

WHO recommends different types of precautions especially for home care for :-

- Home Care for ill People "confirmed Cases"

- Home Care for all members of the household.

- Home Care for Caregivers of coronavirus disease cases.

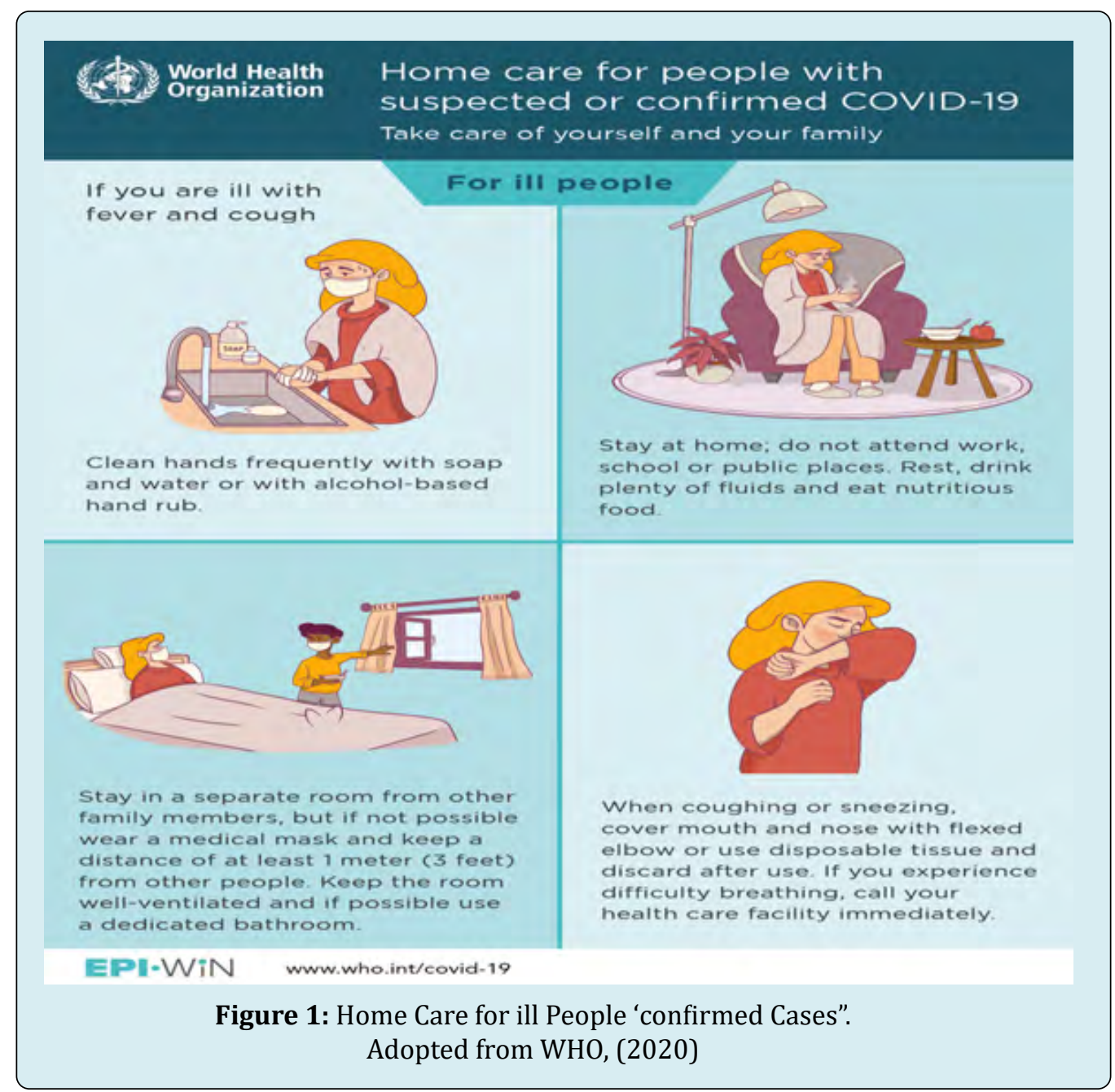

Mohsen MM. Home Care for People with Suspected or Confirmed Coronavirus Disease "Covid-19". Nurs Health Care Int J 2020, 4(S1): 000S1-003. 

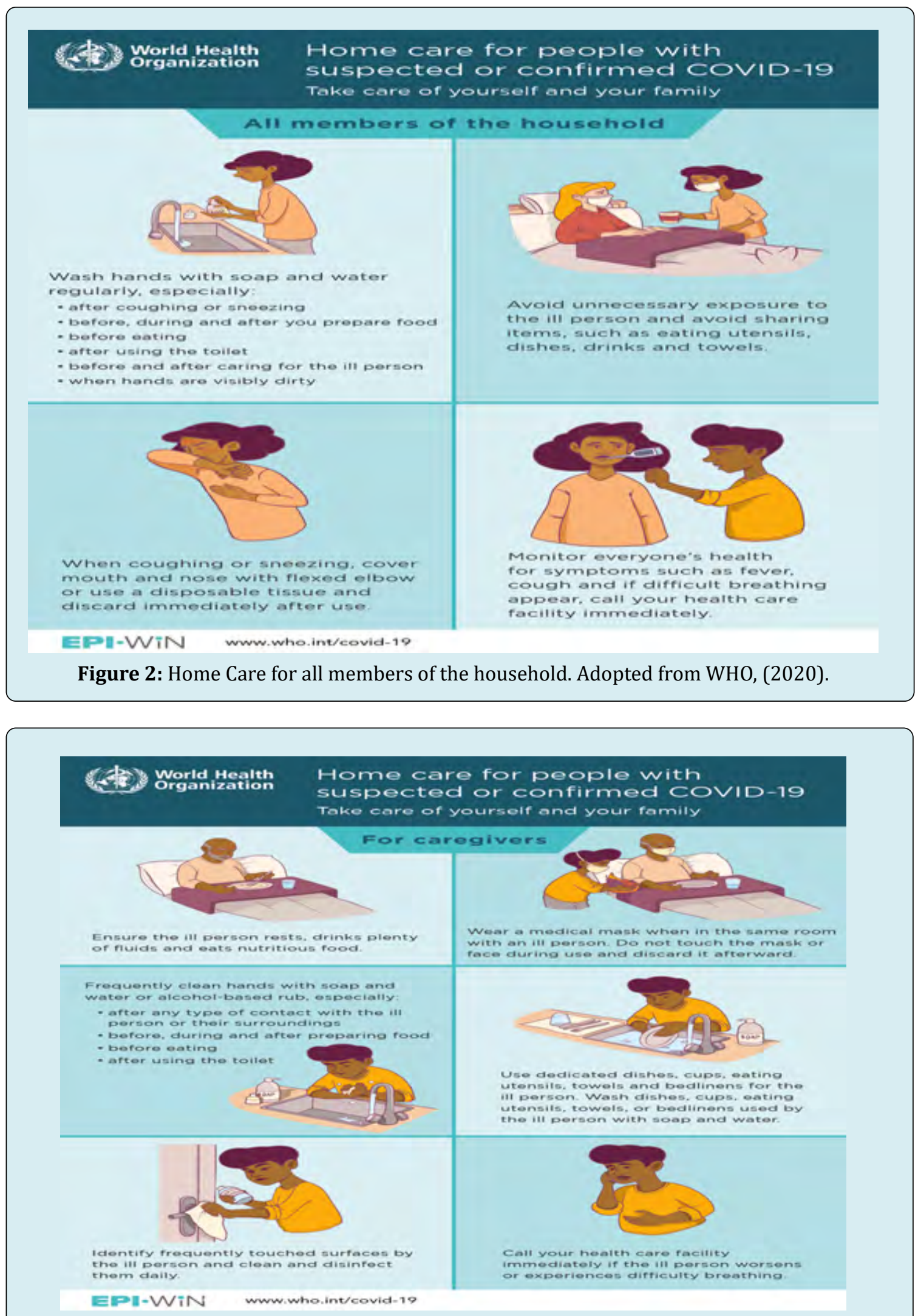

Figure 3: Home Care for Caregivers of coronavirus disease. Adopted from WHO, (2020). 


\section{References}

1. WHO (2020) Pneumonia of Unknown cause- China: disease outbreak news. Geneva: World Health Organization.

2. Fauci AS, Lane HC, Redfield RR (2020) Covid-19Navigation the Uncharted. The New England Journal of Nedicine Med 382: 1268-1269.

3. Liu J, Liao X, Qian S, Yuan J, Wang F, et al. (2020) Community Transmission of Severe Acute Respiratory Syndrome Coronavirus 2, Shenzhen, China. Emerg Infect Dis 26(6): 1320-1323.

4. Li Q, Guan X, Wu P, Wang X, Zhou L, et al. (2020) Early Transmission Dynamics in Wuhan, China, of Novel Coronavirus-Infected Pneumonia. N Engl J Med 382: 1199-1207.

5. COVID-19 (2020) Situation Report - 73. Geneva: World Health Organization, Coronavirus disease 2019.

6. Ong SWX, Tan YK, Chia PY, Lee TH, Ng OT, et al. (2020) Air, Surface Environmental, and Personal Protective Equipment Contamination by Severe Acute Respiratory Syndrome Coronavirus 2 (SARS-CoV-2) From a
Symptomatic Patient. JAMA 323(16): 1610-1612.

7. Yu P, Zhu J, Zhang Z, Han YA (2020) Familial Cluster of Infection Associated With the 2019 Novel Coronavirus Indicating Possible Person-to-Person Transmission During the Incubation Period. J Infect Dis 221(11): 17571761.

8. Lauer SA, Grantz KH, Bi Q Jones FK, Zheng Q Meredith HR, et al., (2020). The Incubation Period of Coronavirus Disease 2019 (COVID-19) From Publicly Reported Confirmed Cases: Estimation and Application. Ann Intern Med 172(9): 577-582.

9. Kimball A, Hatfield KM, Arons M, James A, Taylor J, et al. (2020) Asymptomatic and Pre-symptomatic SARS- CoV2 Infections in Residents of a Long-Term Care Skilled Nursing Facility - King County, Washington, March 2020. MMWR Morb Mortal Wkly Rep 69(13): 377-381.

10. He X, Lau EHY, Wu P, Deng X, Wang J, et al. (2020) Temporal dynamics in viral shedding and transmissibility of COVID-19. Nat Med 26(5): 672-675.

11. WHO (2020) Advice on the Use of masks in the context of COVID-19. 